\title{
Effects of arbuscular mycorrhizal inoculation on uranium and arsenic accumulation by Chinese brake fern (Pteris vittata L.) from a uranium mining-impacted soil
}

\author{
B.D. Chen ${ }^{\text {a }}$, Y.-G. Zhu ${ }^{\text {a,* }}$, F.A. Smith ${ }^{b}$ \\ a Department of Soil Environmental SciencelState Key Lab of Environmental Chemistry and Ecotoxicology, \\ Research Center for Eco-Environmental Sciences, Chinese Academy of Sciences, Beijing 100085, China \\ ${ }^{\mathrm{b}}$ Soil and Land Systems, School of Earth and Environmental Sciences, The University of Adelaide, Adelaide 5005, Australia
}

Received 8 December 2004; received in revised form 24 May 2005; accepted 12 June 2005

Available online 9 August 2005

\begin{abstract}
A glasshouse experiment was conducted to investigate $\mathrm{U}$ and As accumulation by Chinese brake fern, Pteris vittata L., in association with different arbuscular mycorrhizal fungi (AMF) from a $U$ and As contaminated soil. The soil used contains $111 \mathrm{mg} \mathrm{U} \mathrm{kg}^{-1}$ and $106 \mathrm{mg} \mathrm{As} \mathrm{kg}^{-1}$. P. vittata L. was inoculated with each of three AMF, Glomus mosseae, Glomus caledonium and Glomus intraradices. Two harvests were made during plant growth (two and three months after transplanting). Mycorrhizal colonization depressed plant growth particularly at the early stages. TF (transfer factor) values for As from soil to fronds were higher than 1.0, while those for roots were much lower. Despite the growth depressions, AM colonization had no effect on tissue As concentrations. Conversely, TF values for $\mathrm{U}$ were much higher for roots than for fronds, indicating that only very small fraction of $U$ was translocated to fronds (less than $2 \%$ ), regardless of mycorrhizal colonization. Mycorrhizal colonization significantly increased root $U$ concentrations at both harvests. Root colonization with G. mosseae or G. intraradices led to an increase in TF values for U from 7 (non-inoculation control) to 14 at the first harvest. The highest $U$ concentration of $1574 \mathrm{mg} \mathrm{kg}^{-1}$ was recorded in roots colonized by $G$. mosseae at the second harvest. The results suggested that $P$. vittata in combination with appropriate AMF would play very important roles in bioremediation of contaminated environments characterized by a multi-pollution.
\end{abstract}

(c) 2005 Elsevier Ltd. All rights reserved.

Keywords: Arbuscular mycorrhiza; Fern; Uranium; Arsenic; Phytoremediation

\section{Introduction}

Uranium is a common radioactive contaminant in $\mathrm{U}$ mining and processing areas in many parts of the world including China (Ebbs et al., 1998; Xu et al., 2002), and

\footnotetext{
${ }^{*}$ Corresponding author. Tel.: +86106293 6940; fax: +8610 62933563.

E-mail address: ygzhu@mail.rcees.ac.cn (Y.-G. Zhu).
}

it is highly toxic to a broad range of organisms, particularly mammals in terrestrial ecosystems (Fellows et al., 1998). Remediation of U-contaminated soils has thus become an urgent need. Traditional remediation approaches for U-contaminated soils include physical (excavation and disposal) and chemical (extraction/ washing, immobilization) methods (Francis and Dodge, 1998; Zhu and Shaw, 2000). However, these approaches are often very costly, and may significantly reduce soil 
quality and damage the local ecosystem. In recent years, phytoextraction has been proposed as a promising technique for remediating U-contaminated soils (Huang et al., 1998; Zhu and Shaw, 2000; Shahandeh et al., 2001). However, the success of phytoremediation of Ucontaminated soils relies on efficient $U$ uptake and translocation in plants and bioavailability of $U$ in the soils.

The role of AMF in plant uptake of heavy metals has been extensively studied. It is generally agreed that AMF often protect plants against high concentrations of nonessential metals in their shoots by enhancing metal retention in the roots (Leyval et al., 2002). Consequently, AMF could possibly help in revegetation or phytostabilization of metal contaminated sites (Khan et al., 2000; Leyval et al., 2002). It was recently shown that the extraradical AM fungal mycelium took up and translocated $U$ towards roots of in vitro-cultivated mycorrhizas (Rufyikiri et al., 2002, 2003), but U transfer from root to shoot could not be quantified by this model system. In a pot experiment, Rufyikiri et al. (2004) also showed that AMF influenced shoot $U$ concentrations of clover plants but only at high level of $\mathrm{U}$ addition ( $87 \mathrm{mg} \mathrm{U} \mathrm{kg}^{-1}$ soil). Obviously, the impacts of AM fungi on U uptake by plants, especially those having the potential to remediate U-contaminated soils, still need further investigation in order to determine the importance of mycorrhizal fungi in remediation of $\mathrm{U}$-contaminated environments.

On the other hand, arsenic is a ubiquitous contaminant of global concern, and is also a highly toxic element. Arsenic contamination of groundwater and soils (thus food crops) is receiving increasing attention, particularly in Southeast Asia (Meharg and HartleyWhitaker, 2002). Arsenic in the environment is often associated with other elements, such as $\mathrm{Au}, \mathrm{Ag}, \mathrm{Cu}$ and $\mathrm{U}$. U mining and processing activities could cause significant As contamination in the vicinity of mining sites (Pichler et al., 2001; Moldovan et al., 2003). Arsenic concentrations in $\mathrm{U}$ mining tailings can be as high as $6 \mathrm{~g} \mathrm{~kg}^{-1}$ (Moldovan et al., 2003).

Due to the co-existence of $\mathrm{U}$ and As contamination in soils impacted by $U$ mining, the development of remediation approaches for both contaminants becomes necessary. Pteris vittata, Chinese brake fern, has recently been identified as an As hyperaccumulator (Ma et al.,

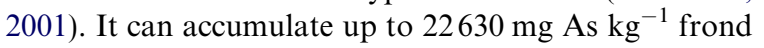
dry weight with a bio-concentration factor of over 10 . After the discovery of $P$. vittata, several other fern species have also been reported to be able to hyperaccumulate As (Zhao et al., 2002). Many studies have demonstrated that phytoextraction of As-contaminated soils using these ferns may be a promising remediation technique. However, so far there is little information available on whether $P$. vittata can also significantly accumulate other metals or metalloids that co-exist with As. If this is the case, then phytoremediation using $P$. vittata may have wide application.
P. vittata forms arbuscular mycorrhizas (Fitz and Wenzel, 2002), but the role of AMF in phytoremediation of As-contaminated soil using this fern plant has received only little attention. Isolates of AMF from an As/ $\mathrm{Cu}$ mine site were shown to be able to maintain a relatively low As concentration in the host plant via efflux (Sharples et al., 2000). However, the enlarged plant biomass due to improved mineral nutrition may still lend advantages to mycorrhizal plants for remediation of As contaminated soils (Liu et al., 2005).

In this study, a soil contaminated by a mixture of $U$ and As was collected from a U mining area and was used to grow $P$. vittata in association with different AMF. The aim was to identify (1) whether $P$. vittata has the potential to extract $U$ from $U$ contaminated environments; (2) the As and $U$ accumulation pattern by $P$. vittata under combined contaminations; (3) the effects of AM colonization on $U$ and As accumulation, and (4) the feasibility to screen effective AMF strains for remediation purposes.

\section{Materials and methods}

\subsection{Host plants and AM fungi}

Spores of Chinese brake fern (P. vittata L.) were collected from Chenzhou, Hu'nan province, China $\left(\mathrm{N} 25^{\circ} 35.360^{\prime \prime}\right.$; E11300.346" $)$. Seedlings were raised from spores in sterilized growth medium (sandy soil mixed with vermiculite at a mixing ratio of $2: 1 \mathrm{v} / \mathrm{v}$ ) in two-litter round plastic pots. Usually it took two weeks for the emergence of tiny gametocytes, and two more weeks for appearance of sporophytes. Till the young sporophytic seedlings had grown up to a height of about $1 \mathrm{~cm}$, they were carefully separated into singles and transplanted immediately into seedling trays for further cultivation in the same growth medium. When the seedlings had two fronds and were about $3 \mathrm{~cm}$ in height, they were ready for transplanting and establishing the experiment.

The AM fungi used were Glomus mosseae (Nicol. \& Gerd.) Gerdemann \& Trappe (BEG167), Glomus caledonium (Nicol. \& Gerd.) Trappe \& Gerdemann and Glomus intraradices Schenck \& Smith (BEG 87). The original inoculum of $G$. caledonium (lab No. 90036) was kindly provided by Professor X.G. Lin of the Institute of Soil Science, Chinese Academy of Sciences. Each fungus was propagated in pot culture with maize plants grown in a sandy soil for 10 weeks. Inoculum from pot culture was a mixture of spores, mycelium, sandy soil and root fragments containing approximately 1000 spores per $100 \mathrm{~g}$.

\subsection{Growth medium}

The growth medium was a sandy soil collected from a $\mathrm{U}$ mining site in Shangrao County, Jiangxi province, 
China. Before the experiment, the soil was passed through a $2 \mathrm{~mm}$ sieve, partially sterilized $(10 \mathrm{kGy}$, $10 \mathrm{MeV}$ electron beam) and amended with basal nutrients without $\mathrm{P}$ as recommended by Pearson and Jakobsen (1993). Soil pH was 8.23 (1:2.5 soil to water). The soil had a final extractable $\mathrm{P}$ content of $4.23 \mathrm{mg} \mathrm{kg}^{-1}$ (extracted by $0.5 \mathrm{M} \mathrm{NaHCO}_{3}$ using the methods established by Olsen et al., 1954) and $\mathrm{CaCO}_{3}$ equivalent content of $77.8 \mathrm{~g} \mathrm{~kg}^{-1}$. Total $\mathrm{U}$ content was $111 \mathrm{mg} \mathrm{U} \mathrm{kg}^{-1}$, and exchangeable and carbonate- $\mathrm{U}$ (following the methods described by Shahandeh and Hossner, 2002) were 8.9 and $29.3 \mathrm{mg} \mathrm{kg}^{-1}$ soil, respectively. Total As content was $106 \mathrm{mg} \mathrm{As} \mathrm{kg}^{-1}$, and water extractable As (soil: water $=1: 10$ ) was $5.9 \mathrm{mg} \mathrm{kg}^{-1}$ soil.

\subsection{Experimental procedures}

Round plastic pots were used, each containing $940 \mathrm{~g}$ of the soil. Inoculated treatments received $60 \mathrm{~g}$ of the fungal inoculum, which was carefully mixed into the growth medium, while non-inoculated plants received equivalent amount of autoclaved soil-sand mixture. Each pot was transplanted with one seedling. The resulting four treatments had eight replicates and the 32 pots were arranged in a randomized block design. The experiment was established on 16 June 2003 and conducted in a controlled environment glass house with $16 \mathrm{~h}-25^{\circ} \mathrm{C}$ day and $8 \mathrm{~h}-18^{\circ} \mathrm{C}$ night and natural light. De-ionized water was added as required to maintain moisture content at $55 \%$ of water holding capacity by regular weighing. Nitrogen (as $\mathrm{NH}_{4} \mathrm{NO}_{3}$ ) was added to the pots 30 and $45 \mathrm{~d}$ after transplanting to provide a total of $120 \mathrm{mg} \mathrm{N}$ per pot. The first harvest was made two months after transplanting on 15 August 2003. Four replicates of each treatment were harvested and the remaining pots were harvested on 10 September 2003.

\subsection{Harvest and chemical analysis}

Fronds and roots were harvested separately. Soil samples were collected for determination of hyphal length density. Root samples were then carefully washed with tap water followed by deionised water to remove adhering soil particles. Sub-samples of fresh roots were collected for the determination of AM colonization as described below. The dry weights of fronds and roots were determined after oven drying at $70^{\circ} \mathrm{C}$ for $48 \mathrm{~h}$. Oven-dried sub-samples were milled and digested by acid digestion using a mixture of $\mathrm{HNO}_{3}$ and $\mathrm{HClO}_{4}$ $(4: 1 \mathrm{v} / \mathrm{v})$ at $225^{\circ} \mathrm{C}$. The dissolved samples were analyzed for uranium $\left({ }^{238} \mathrm{U}\right)$ on inductively coupled plasma-mass spectroscopy (ICP-MS) (Finnigan Mat, Germany) without any radiochemical treatment. The uranium isotope ${ }^{233} \mathrm{U}$ was used as an internal standard. Arsenic concentrations were determined using an atomic fluorescence spectrometer (Model AF-610A, Beijing Rayleigh Ana- lytical Instrument Co., China), while P was analyzed using the molybdo-phosphovanado-molybdate method (Hanson, 1950).

Sub-samples of fresh roots were cleared in $10 \% \mathrm{KOH}$ and stained with Trypan blue by the procedure of Phillips and Hayman (1970), modified to omit phenol from solutions and $\mathrm{HCl}$ from the rinse. Percentage root colonization and root length were determined by the gridintersect method (Giovanetti and Mosse, 1980).

\subsection{Data analysis}

The transfer factor (TF) was defined as the ratios of elemental concentrations in plant tissues $\left(\mathrm{mg} \mathrm{kg}^{-1}\right.$ d.w.) to those in the soil $\left(\mathrm{mg} \mathrm{kg}^{-1}\right.$ d.w.); this parameter was used to evaluate the phytoextraction efficiency.

All data were subjected to two-way ANOVA to compare harvest and inoculation treatment using GenStat for PC/Windows 6.1 (GenStat Committee, 2002). Multi-comparisons by least significant difference (LSD) at the $5 \%$ level were applied to compare means of inoculation treatments across the two harvests, where harvest and inoculation interacted, or within each harvest where there were no significant interactions.

\section{Results}

\subsection{Colonization of roots by different AM fungi}

Table 1 shows that the root colonization with three AMF ranged from $22 \%$ to $63 \%$ at the first harvest. There was a general decrease in the colonization rates from the first to the second harvest $(P<0.001)$ for $G$. mosseae and G. caledonium. At the first harvest (Table 1),

Table 1

Root colonization and extraradical hyphal length density of Chinese brake fern inoculated with different AM fungi

\begin{tabular}{|c|c|c|}
\hline \multirow[t]{2}{*}{ Inoculation treatment } & \multicolumn{2}{|c|}{ Root colonization $(\%)$} \\
\hline & $\begin{array}{l}\text { First } \\
\text { harvest }\end{array}$ & $\begin{array}{l}\text { Second } \\
\text { harvest }\end{array}$ \\
\hline$\overline{-M}$ & 0 & 0 \\
\hline Glm & 63 & 27 \\
\hline Glc & 41 & 28 \\
\hline Gli & 22 & 23 \\
\hline LSD & \multicolumn{2}{|c|}{11} \\
\hline Significance $^{\mathrm{a}}$ of & \\
\hline Harvest & \multicolumn{2}{|c|}{$* * *$} \\
\hline Inoculation & \multicolumn{2}{|c|}{$* * *$} \\
\hline Interaction & \multicolumn{2}{|c|}{$* * *$} \\
\hline
\end{tabular}

-M, non-mycorrhizal; Glm, G. mosseae; Glc, G. caledonium; Gli, G. intraradices.

${ }^{\mathrm{a}}$ By analysis of variance. ${ }^{* * *} P<0.001$. 
G. mosseae produced significantly higher colonization than the other two fungi $(P<0.001)$, while the differences in colonization among the three AMF treatments were not noted at the second harvest.

\subsection{Plant growth}

Plant dry weights increased markedly from the first to the second harvest $(P<0.001)$ (Fig. 1). At the first harvest, mycorrhizal colonization generally decreased plant dry weights $(P<0.001)$, and plants inoculated with $G$. intraradices had the smallest dry weight. At the second harvest, only the inoculation with $G$. intraradices produced a small growth depression compared with non-inoculated controls, and no significant differences was observed among inoculation with $G$. mosseae, G. caledonium and the control.

\subsection{Plant phosphorus nutrition}

Mycorrhizal colonization led to an overall increase in $\mathrm{P}$ concentrations at the first harvest but the beneficial
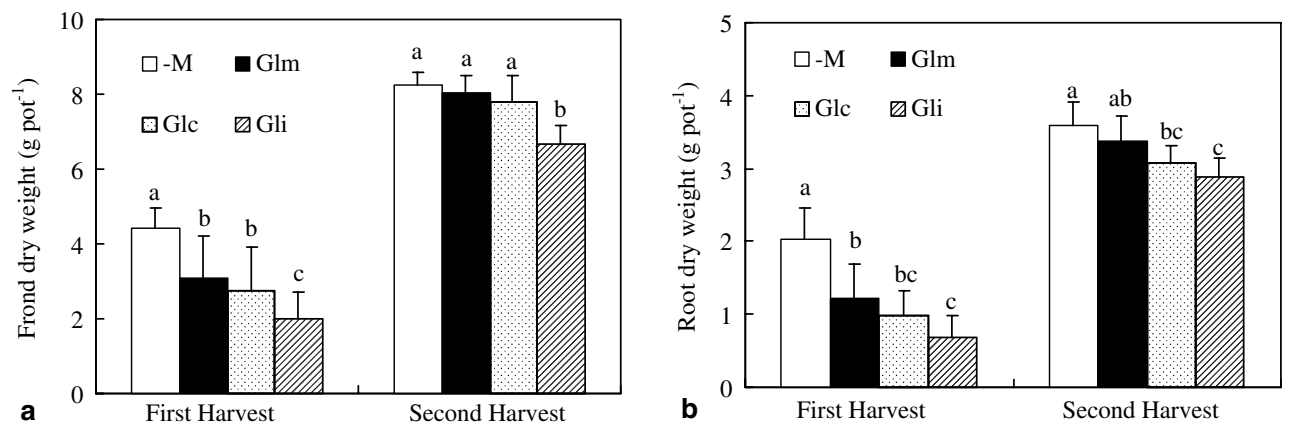

Fig. 1. Frond (a) and root (b) dry weight of Chinese brake fern inoculated with different AM fungi. -M, Glm, Glc and Gli represent non-inoculation control and inoculation with $G$. mosseae, G. caledonium and G. intraradices, respectively. By analysis of variance, harvest and inoculation were highly significant $(P<0.001)$ for both fronds and roots. Different letters above columns indicate significant differences among inoculation treatments at each harvest by LSD multi-comparison at the $5 \%$ level.

Table 2

$\mathrm{P}$ concentration and uptake in Chinese brake fern inoculated with different AM fungi

\begin{tabular}{|c|c|c|c|c|c|}
\hline & \multirow[t]{2}{*}{ Inoculation treatment } & \multicolumn{2}{|c|}{$\mathrm{P}$ concentration $\left(\mathrm{mg} \mathrm{g}^{-1}\right)$} & \multicolumn{2}{|c|}{$\mathrm{P}$ uptake $\left(\mathrm{mg} \mathrm{pot}^{-1}\right)$} \\
\hline & & $\begin{array}{l}\text { First } \\
\text { harvest }\end{array}$ & $\begin{array}{l}\text { Second } \\
\text { harvest }\end{array}$ & $\begin{array}{l}\text { First } \\
\text { harvest }\end{array}$ & $\begin{array}{l}\text { Second } \\
\text { harvest }\end{array}$ \\
\hline \multirow[t]{4}{*}{ Frond } & $-\mathrm{M}$ & 1.54 & 1.49 & 6.81 & 12.26 \\
\hline & Glm & 1.84 & 1.52 & 5.54 & 12.21 \\
\hline & Glc & 1.91 & 1.59 & 5.22 & 12.39 \\
\hline & Gli & 2.02 & 1.66 & 4.03 & 11.10 \\
\hline LSD & & \multicolumn{2}{|c|}{0.13} & \multicolumn{2}{|c|}{1.20} \\
\hline \multicolumn{6}{|l|}{ Significance $^{\mathrm{a}}$ of } \\
\hline Harvest & & \multicolumn{2}{|c|}{ *** } & \multicolumn{2}{|c|}{$* * *$} \\
\hline Inoculation & & \multicolumn{2}{|c|}{$* * *$} & \multicolumn{2}{|c|}{ * } \\
\hline Interaction & & \multicolumn{2}{|c|}{$*$} & \multicolumn{2}{|c|}{ NS } \\
\hline \multirow[t]{4}{*}{ Root } & $-\mathrm{M}$ & 1.56 & 1.60 & 3.15 & 5.77 \\
\hline & Glm & 1.71 & 1.61 & 2.05 & 5.42 \\
\hline & Glc & 1.75 & 1.69 & 1.72 & 5.18 \\
\hline & Gli & 1.81 & 1.70 & 1.24 & 4.89 \\
\hline LSD & & \multicolumn{2}{|c|}{0.08} & \multicolumn{2}{|c|}{0.59} \\
\hline \multicolumn{6}{|l|}{ Significance of } \\
\hline Harvest & & \multicolumn{2}{|c|}{$*$} & \multicolumn{2}{|c|}{$* * *$} \\
\hline Inoculation & & \multicolumn{2}{|c|}{${ }^{* * * *}$} & \multicolumn{2}{|c|}{$* * *$} \\
\hline Interaction & & \multicolumn{2}{|c|}{ NS } & \multicolumn{2}{|c|}{ NS } \\
\hline
\end{tabular}

-M, non-mycorrhizal; Glm, G. mosseae; Glc, G. caledonium; Gli, G. intraradices.

${ }^{\text {a }}$ By analysis of variance. ${ }^{* * *} P<0.001$; ${ }^{*} P<0.05$; NS, not significant. 
effect weakened at the second harvest (Table 2). At the first harvest, mycorrhizal colonization significantly reduced total $\mathrm{P}$ uptake $(P<0.001)$. At the second harvest, no difference in total $\mathrm{P}$ uptake was observed between the treatments.

\subsection{Arsenic uptake and partitioning}

Mycorrhizal colonization had no effect on As concentration (Table 3). At the first harvest, mycorrhizal colonization significantly reduced As uptake into fronds and roots $(P<0.01)$, but the difference was not noted at the second harvest. Transfer factors (TF) for As from soil to fronds were higher than 1 , while those for roots were much lower. TF for the first harvest were higher than for the second harvest and mycorrhizal colonization had no significant effect. At the first harvest, average TF for fronds was 1.83 and that for roots was 0.79 ; while at the second harvest, average TF for fronds was 1.34 and that for roots was 0.59 .

$\mathrm{P} /$ As ratios in both fronds $(P<0.001)$ and roots $(P<0.01)$ were higher at the second harvest than at the first harvest (Fig. 2). Inoculation treatment affected only $\mathrm{P} /$ As ratios in fronds $(P<0.05)$; at the first harvest, the ratios were significantly increased by inoculation with G. mosseae and G. caledonium.

\subsection{Uranium uptake and partitioning}

Frond $\mathrm{U}$ concentrations were significantly higher at the second harvest than at the first harvest $(P<0.001)$ except for the plants colonized by $G$. caledonium, but in general root $\mathrm{U}$ concentrations did not differ between the two harvests (Table 4). At the first harvest mycorrhizal colonization increased frond $\mathrm{U}$ concentrations $(P<0.01)$. At the second harvest plants colonized with $G$. intraradices had significantly higher frond U concentrations compared to non-inoculated plants, and plants colonized with $G$. caledonium had significantly lower frond $\mathrm{U}$ concentrations than non-inoculated plants. Mycorrhizal colonization significantly increased root $\mathrm{U}$ concentrations at both harvests $(P<0.01)$ except for plants colonized by G. caledonium at the second harvest.

Total U uptake was significantly higher at the second harvest than at the first harvest $(P<0.001$, Table 4$)$. Mycorrhizal colonization did not affect $U$ accumulation in fern fronds and roots at the first harvest; while at the second harvest, colonization with G. caledonium deceased $U$ accumulation in fronds and did not affect $U$ accumulation in roots. In contrast, colonization by G. mosseae or G. intraradices did not affect U accumulation in fronds but significantly increased $U$ accumula-

Table 3

Arsenic concentration and uptake in Chinese brake fern inoculated with different AM fungi

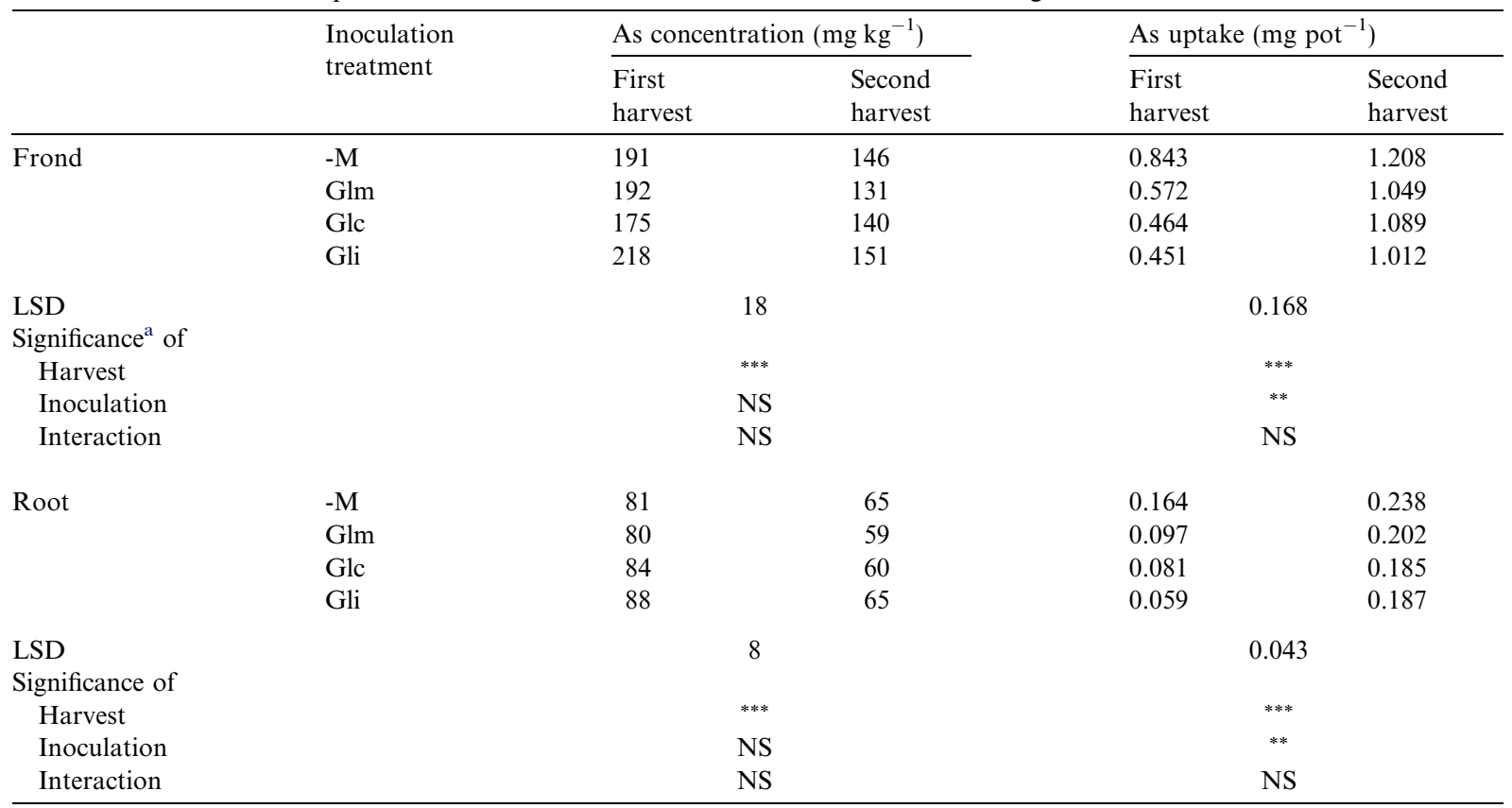

-M, non-mycorrhizal; Glm, G. mosseae; Glc, G. caledonium; Gli, G. intraradices.

${ }^{a}$ By analysis of variance. ${ }^{* * *} P<0.001 ;{ }^{* *} P<0.01$; NS, not significant. 

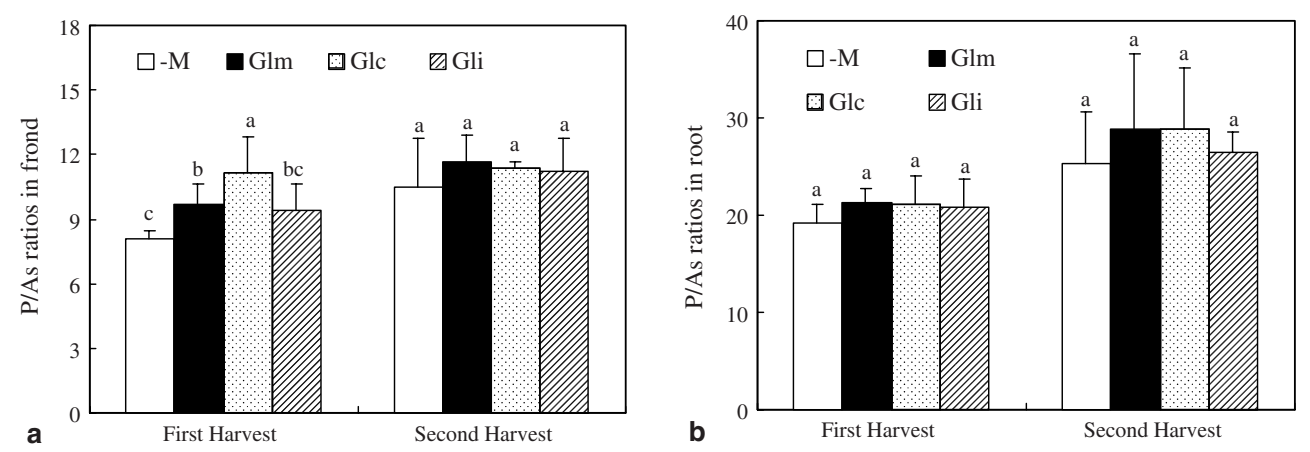

Fig. 2. P/As ratios in frond (a) and root (b) of Chinese brake fern inoculated with different AM fungi. -M, Glm, Glc and Gli represent non-inoculation control and inoculation with G. mosseae, G. caledonium and G. intraradices, respectively. By analysis of variance, harvest was highly significant for both fronds $(P<0.01)$ and roots $(P<0.001)$, while inoculation was significant for only fronds $(P<0.05)$. Different letters above columns indicate significant differences among inoculation treatments at each harvest by LSD multicomparison at the $5 \%$ level.

Table 4

${ }^{238} \mathrm{U}$ concentration and uptake in Chinese brake fern inoculated with different AM fungi

\begin{tabular}{|c|c|c|c|c|c|}
\hline & \multirow{2}{*}{$\begin{array}{l}\text { Inoculation } \\
\text { treatment }\end{array}$} & \multicolumn{2}{|c|}{${ }^{238} \mathrm{U}$ concentration $\left(\mathrm{mg} \mathrm{kg}^{-1}\right)$} & \multicolumn{2}{|c|}{${ }^{238} \mathrm{U}$ uptake $\left(\mu \mathrm{g}\right.$ pot $\left.{ }^{-1}\right)$} \\
\hline & & $\begin{array}{l}\text { First } \\
\text { harvest }\end{array}$ & $\begin{array}{l}\text { Second } \\
\text { harvest }\end{array}$ & $\begin{array}{l}\text { First } \\
\text { harvest }\end{array}$ & $\begin{array}{l}\text { Second } \\
\text { harvest }\end{array}$ \\
\hline \multirow[t]{4}{*}{ Frond } & $-M$ & 2.08 & 6.85 & 9.36 & 56.30 \\
\hline & Glm & 2.69 & 6.17 & 8.45 & 49.77 \\
\hline & Glc & 4.16 & 4.09 & 9.55 & 31.45 \\
\hline & Gli & 4.97 & 9.03 & 9.83 & 60.86 \\
\hline LSD & & \multicolumn{2}{|c|}{2.31} & \multicolumn{2}{|c|}{14.83} \\
\hline \multicolumn{6}{|l|}{ Significance ${ }^{\mathrm{a}}$ of } \\
\hline Harvest & & \multicolumn{2}{|c|}{$* * *$} & \multicolumn{2}{|c|}{$* * *$} \\
\hline Inoculation & & \multicolumn{2}{|c|}{$* *$} & \multicolumn{2}{|c|}{$*$} \\
\hline Interaction & & \multicolumn{2}{|c|}{$*$} & \multicolumn{2}{|c|}{$*$} \\
\hline \multirow[t]{4}{*}{ Root } & $-M$ & 776 & 1027 & 1525 & 3722 \\
\hline & Glm & 1040 & 1574 & 1298 & 5259 \\
\hline & Glc & 1453 & 1128 & 1387 & 3420 \\
\hline & Gli & 1534 & 1511 & 963 & 4321 \\
\hline LSD & & \multicolumn{2}{|c|}{436} & \multicolumn{2}{|c|}{843} \\
\hline \multicolumn{6}{|l|}{ Significance of } \\
\hline Harvest & & \multicolumn{2}{|c|}{ NS } & \multicolumn{2}{|c|}{$* * *$} \\
\hline Inoculation & & \multicolumn{2}{|c|}{$* *$} & \multicolumn{2}{|c|}{$*$} \\
\hline Interaction & & \multicolumn{2}{|c|}{$*$} & \multicolumn{2}{|c|}{$* *$} \\
\hline
\end{tabular}

-M, non-mycorrhizal; Glm, G. mosseae; Glc, G. caledonium; Gli, G. intraradices.

${ }^{\mathrm{a}}$ By analysis of variance. ${ }^{* * *} P<0.001 ;{ }^{* *} P<0.01 ;{ }^{*} P<0.05$; NS, not significant.

tion in roots compared with non-mycorrhizal plants and those colonized by G. caledonium.

The frond to root ratios of total U uptake indicated that only a very small fraction of $U$ was translocated to fronds (less than $2 \%$, Fig. 3). The ratios were generally higher at the second than the first harvest $(P<0.01)$, not significantly affected by mycorrhizal colonization. $T F$ values of $U$ were much higher for roots than for fronds. For fronds the TF values were higher at the sec- ond than at the first harvest $(P<0.001)$, but for roots there were no obvious differences (Fig. 4). There were significant interactions between harvest and inoculation recorded $(P<0.05)$. At the first harvest, mycorrhizal colonization tended to increase TF values for both the fronds and roots. At the second harvest, colonization with $G$. intraradices increased TF values for both fronds and roots, and colonization with $G$. mosseae increased the TF value for the roots. 


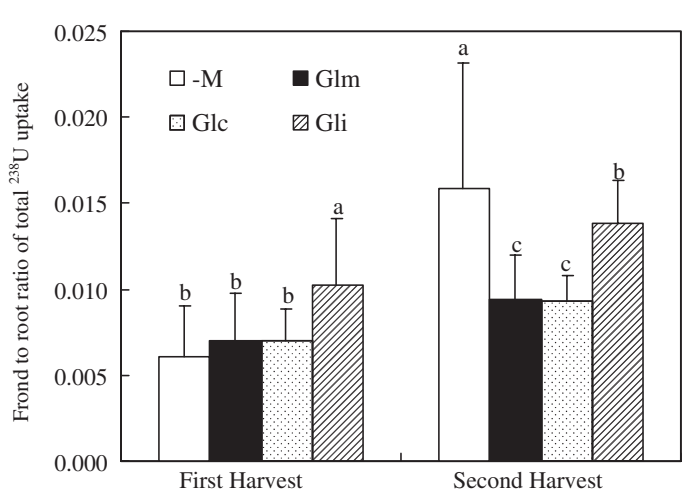

Fig. 3. Frond to root ratio of total $U$ uptake by Chinese brake fern inoculated with different AM fungi. -M, Glm, Glc and Gli represent non-inoculation control and inoculation with $G$. mosseae, G. caledonium and $G$. intraradices, respectively. By analysis of variance, $U$ translocation ratios were only influenced by harvest $(P<0.001)$. Different letters above columns indicate significant differences among inoculation treatments at each harvest by LSD multi-comparison at the 5\% level.

\section{Discussion}

The Chinese brake fern, $P$. vittata can hyperaccumulate As with a TF value greater than 10 (Ma et al., 2001). However, the TF values can be influenced by various soil and plant factors, such as As speciation in soils (Tu and Ma, 2002). TF values of $P$. vittata grown in field soils in China were between 0.07 and 7.42, decreasing with increasing soil As concentrations (Chen et al., 2002), and were generally lower than those reported by Ma et al. (2001) and Tu and Ma (2002). The ecotype of $P$. vittata was the same used in the present study as in the study by Chen et al. (2002), and the TF values we observed were similar to their report. $P$. vittata is a mycorrhizal plant, and in the present study roots of $P$. vittata were highly colonized by different strains of AMF. However, mycorrhizal colonization depressed plant growth under our experimental conditions, particularly at the early stages. Growth depressions are not uncommon in mycorrhizal plants (Peng et al., 1993; Graham and Abbott, 2000), and are usually believed to result from carbon drain to the AM fungus that exceeds growth benefits from improved mineral nutrition (Johnson et al., 1997). In addition, $U$ is known to be highly toxic to plants (Fellows et al., 1998), and the predicted no-effect concentration for chemical toxicity of $U$ to terrestrial plants was proposed as $250 \mathrm{mg} \mathrm{U} \mathrm{kg}^{-1}$ dry soil (Sheppard et al., 2005). Although soil U concentration was lower than this value in present study, $\mathrm{U}$ accumulated in roots of $P$. vittata to such high concentration could also possibly lead to U phytotoxicity, and thus other explanation of growth depression by AMF could possibly be $\mathrm{U}$ toxicity due to AM-mediated enhanced $\mathrm{U}$ concentrations in roots.

Despite the growth depression, mycorrhizal colonization tended to increase $\mathrm{P}$ concentration (especially at the first harvest) but had no effect on As concentration. This has resulted in increased P/As ratios and may enhance arsenic resistance of the brake fern. Sharples et al. (2000) reported that Calluna vulgaris formed an ericoid mycorrhizal association and the mycorrhizal fungus, Hymenoscyphus ericae, played a major role in plant resistance to As by selectively accumulating phosphate over arsenate. The work of Gonzalez-Chavez et al. (2002) demonstrated that AMF on mine spoils have evolved arsenate resistance, and conferred enhanced resistance on Holcus lanatus. The AMF strains used in present study were initially not isolated from contaminated areas, but still indicated the potential to facilitate $\mathrm{P}$ uptake under experimental conditions, which might help host plants surviving As contaminations. It's
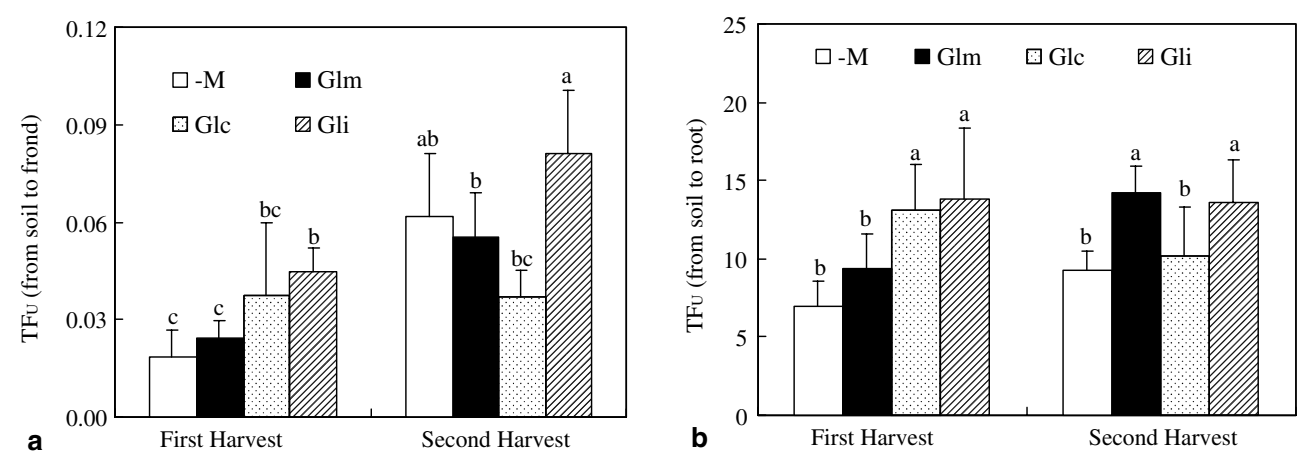

Fig. 4. U transfer factor (TF) of Chinese brake fern from soil to fronds (a) and roots (b). -M, Glm, Glc and Gli represent noninoculation control and inoculation with $G$. mosseae, $G$. caledonium and $G$. intraradices, respectively. By analysis of variance, harvest was highly significant for only fronds $(P<0.001)$, while inoculation was highly significant $(P<0.01)$ for both fronds and roots. Significant interaction $(P<0.05)$ of harvest with inoculation was observed for both fronds and roots. Different letters above columns indicate significant differences among inoculation treatments across harvests by LSD multi-comparison at the $5 \%$ level. 
noticeable that under experimental conditions, due to growth depression by mycorrhizal colonization AMF did not increase total As uptake by Chinese brake fern, which was not in accordance with the findings by Liu et al. (2005). Quite obviously further investigations are needed to optimize the mycorrhizal associations, and the results also suggested that cautious considerations should be taken when introducing AMF into the phytoremediation strategies.

Phytoextraction has been proposed as a possible technique to clean up U-contaminated soils. Successful phytoextraction depends on the identification of a plant species capable of both taking up and translocating $U$ aboveground, and the development of agronomic and/ or amendment strategies to improve plant growth and the bioavailability of $U$ in soils (Ebbs et al., 1998). Apart from chemical amendments, biological amendments, such as mycorrhizal symbiosis, have also been suggested to be included in phytoremediation (Khan et al., 2000; Leyval et al., 2002). To our knowledge, the present study is the first one addressing the effects of AMF on plant uptake of As and $U$ from soil contaminated with a mixture of As and U. Our data demonstrated that the Chinese brake fern could highly accumulate $U$, with TF values for roots as high as 14 , which were much higher than those reported so far (e.g., for sunflower and Indian mustard root bioaccumulation coefficients were 8.1 and 5.4, respectively; Shahandeh and Hossner, 2002). TF values for the roots were increased by the inoculation with AMF, especially for $G$. intraradices. However, translocation of $U$ from the roots to the fronds was relatively low, and was also observed in many other plants (Saric et al., 1995; Shahandeh and Hossner, 2002). It is possible that the high TF values in mycorrhizal roots were the result of adsorption of $U$ on or in mycorrhizal hyphae, and also likely $U$ accumulation in intraradical hyphae due to efficient $U$ translocation via hyphal pathway. It has been reported that $\mathrm{U}$ concentrations in mycorrhizal hyphae could be 5.5 and 9.6 times higher than for the mycorrhizal and non-mycorrhizal roots (Rufyikiri et al., 2003), respectively. Weiersbye et al. (1999) revealed that in mycorrhiza of Cynodon dactylon $\mathrm{U}$ accumulated in fungal vesicles, and decreased $U$ translocation from plant roots to shoots were observed in very recent studies (Rufyikiri et al., 2004; Chen et al., 2005). These studies strongly supported the potential use of AMF to stabilize $\mathrm{U}$ contaminated environments.

Rhizofiltration, namely to remove contaminants using plants with extensive root systems and high accumulation capacity for contaminants, was proposed as one of the novel approaches for cleaning up of waste water. Some researchers noticed that sunflower could accumulate $U$ in the roots with concentrations 5000 10000 times greater than that in the water (Entry et al., 1996). This plant also produces large biomass, and as a result was considered as best candidate for treatment of U contaminated water (Dushenkov et al., 1995; Salt et al., 1995; Entry et al., 1996). Chinese brake fern is also reported as fast growing and high biomass plant with particular tolerance to As (Ma et al., 2001), and therefore it can be exploited for rhizofiltration purposes especially on As and $U$ combined contaminated sites. The $U$ sequestration in the fern would be further improved by introducing AMF into the system because of the high $U$ accumulation in mycorrhizal roots. Thus mycorrhizal colonization may not only improve in situ retention of $U$ by the Chinese brake fern, but may also increase $U$ retention by the vast extraradical AMF hyphal network in the soil.

In conclusion, under U-As combined contamination TF values for As from soil to fronds of $P$. vittata were higher than 1.0, while AM colonization caused growth depressions but had no effect on tissue As concentrations. More importantly, to our knowledge the present study is the first one that addresses effects of AMF on plant uptake of As and $\mathrm{U}$ from the soil contaminated with a mixture of As and U. Our data demonstrated that the Chinese brake fern could highly accumulate $U$ in roots. It could be planted on $\mathrm{U}$ mining tailings and near drainage sites for mining wastewater. The high levels of $\mathrm{U}$ sequestration in roots of the fern could retain $U$ in situ, thus reduce the off-site impacts of $U$ mining and processing activities. Due to the fact that symbiotic association to certain extent enhanced $U$ accumulation in roots, $\mathrm{U}$ sequestration could be further improved by introducing AMF into the system. The variations in mycorrhizal effects on $U$ accumulation supported the feasibility of screening effective AM fungal strains for remediation purposes.

\section{Acknowledgements}

This work was financially supported by the Natural Science Foundation of China (40401031 and 40321101) and Ministry of Science and Technology of China (2002CB410808, 2001AA645010-4).

\section{References}

Chen, T.B., Wei, C.Y., Huang, Z.C., Lu, Q.G., Fan, Z.L., 2002. Arsenic hyperaccumulator Pteris vittata $\mathrm{L}$. and its arsenic accumulation. Chin. Sci. Bull. 47, 902-905.

Chen, B.D., Roos, P., Borggaard, O.K., Zhu, Y.-G., Jakobsen, I., 2005. Mycorrhiza and root hairs in barley enhance acquisition of phosphorus and uranium from phosphate rock but mycorrhiza decreases root to shoot uranium transfer. New Phytol. 165, 591-598.

Dushenkov, V., Kumar, N.P.B.A., Motto, H., Raskin, I., 1995. Rhizo-filtration: the use of plants to remove heavy metals from aqueous streams. Environ. Sci. Technol. 29, 12391245. 
Ebbs, S.D., Brady, D.J., Kochian, L.V., 1998. Role of uranium speciation in the uptake and translocation of uranium by plants. J. Exp. Bot. 49, 1183-1190.

Entry, J.A., Vance, N.C., Hamilton, M.A., Zabowski, D., Watrud, L.S., Adriano, D.C., 1996. Phytoremediation of soil contaminated with low concentrations of radionuclides. Water Air Soil Pollut. 88, 167-176.

Fellows, R.J., Ainsworth, C.C., Driver, C.J., Catoldo, D.A., 1998. Dynamics and transformation of radionuclides in soils and ecosystem health. In: Soil Chemistry and Ecosystem Health. Soil Sci. Soc. Am., Madison, WI, USA, pp. 85-131.

Fitz, W.J., Wenzel, W.W., 2002. Arsenic transformations in the soil-rhizosphere-plant system: fundamentals and potential application to phytoremediation. J. Biotech. 99, 259-278.

Francis, A.J., Dodge, C.J., 1998. Remediation of soils and wastes contaminated with uranium and toxic metals. Environ. Sci. Technol. 32, 3993-3998.

GenStat Committee, 2002. Payne, R.W. (Ed.), The guide to GenStat release 6.1-Part 1: Syntax and data management. VSN International, Hemel Hempstead, UK.

Giovanetti, M., Mosse, B., 1980. An evaluation of techniques for measuring vesicular arbuscular mycorrhizal infection in roots. New Phytol. 84, 489-500.

Gonzalez-Chavez, C., Harris, P.J., Dodd, J., Meharg, A.A., 2002. Arbuscular mycorrhizal fungi confer enhanced arsenate resistance on Holcus lanatus. New Phytol. 155, 163171.

Graham, J.H., Abbott, L.K., 2000. Wheat responses to aggressive and non-aggressive arbuscular mycorrhizal fungi. Plant Soil 220, 207-218.

Hanson, W.C., 1950. The photometric determination of phosphorus in fertilisers using the phosphovanado-molybdate complex. J. Sci. Food Agr. 1, 172-173.

Huang, J.W., Blaylock, M.J., Kapulnik, Y., Ensley, B.D., 1998. Phytoremediation of uranium- contaminated soils: role of organic acids in triggering uranium hyperaccumulation in plants. Environ. Sci. Technol. 32, 2004-2008.

Johnson, N.C., Graham, J.H., Smith, F.A., 1997. Functioning of mycorrhizal associations along the mutualism-parasitism continuum. New Phytol. 135, 575-585.

Khan, A.G., Kuek, C., Chaudhry, T.M., Khoo, C.S., Hayes, W.J., 2000. Role of plants, mycorhizae and phytochelators in heavy metal contaminated land remediation. Chemosphere 41, 197-207.

Leyval, C., Joner, E.J., del Val, C., Haselwandter, K., 2002. Potential of arbuscular mycorrhizal fungi for bioremediation. In: Gianinazzi, S., Schüepp, H., Barea, J.M., Haselwandter, K. (Eds.), Mycorrhizal Technology in Agriculture. Birkhäuser Verlag, Basel, Switzerland, pp. 175-186.

Liu, Y., Zhu, Y.-G., Chen, B.D., Christie, P., Li, X.L., 2005. Influence of the arbuscular mycorrhizal fungus Glomus mosseae on uptake of arsenate by the As hyperaccumulator fern Pteris vittata L. Mycorrhiza 15, 187-192.

Ma, L.Q., Komar, K.M., Tu, C., Zhang, W.H., Cai, Y., Kennelley, E.D., 2001. A fern that hyperaccumulates arsenic. Nature 409, 579.

Meharg, A.A., Hartley-Whitaker, J., 2002. Arsenic uptake and metabolism in arsenic resistant and nonresistant plant species. New Phytol. 154, 29-43.

Moldovan, B.J., Jiang, D.T., Hendry, M.J., 2003. Mineralogical characterization of arsenic in uranium mine tailings precipitated from iron-rich hydrometallurgical solutions. Environ. Sci. Technol. 37, 873-879.

Olsen, S.R., Cole, C.V., Watanabe, F.S., Dean, L.A., 1954. Estimation of available phosphorus in soils by extraction with sodium bicarbonate. USDA Agric. Circ. 939, 1-19.

Pearson, J.N., Jakobsen, I., 1993. The relative contribution of hyphae and roots to phosphorus uptake by arbuscular mycorrhizal plants measured by dual labelling with ${ }^{32} \mathrm{P}$ and ${ }^{33}$ P. New Phytol. 124, 489-494.

Peng, S.B., Eissenstat, D.M., Graham, J.H., Williams, K., Hodge, N.C., 1993. Growth depression in mycorrhizal citrus at high phosphorus supply: analysis of carbon costs. Plant Physiol. 101, 1063-1071.

Phillips, J.M., Hayman, D.S., 1970. Improved procedures for clearing and staining parasitic and vesicular-arbuscular mycorrhizal fungi for rapid assessment of infection. Trans. Br. Mycol. Soc. 55, 158-161.

Pichler, T., Hendry, M.J., Hall, G.E.M., 2001. The mineralogy of arsenic in uranium mine tailings at the rabbit lake in-pit facility, northern Saskatchewan, Canada. Environ. Geol. 40, 495-506.

Rufyikiri, G., Thiry, Y., Wang, L., Delvaux, B., Declerck, S., 2002. Uranium uptake and translocation by the arbuscular mycorrhizal fungus, Glomus intraradices, under root-organ culture conditions. New Phytol. 156, 275-281.

Rufyikiri, G., Thiry, Y., Declerck, S., 2003. Contribution of hyphae and roots to uranium uptake and translocation by arbuscular mycorrhizal carrot roots under root-organ culture conditions. New Phytol. 158, 391-399.

Rufyikiri, G., Huysmans, L., Wannijn, J., Van Hees, M., Leyval, C., Jakobsen, I., 2004. Arbuscular mycorrhizal fungi can decrease the uptake of uranium by subterranean clover grown at high levels of uranium in soil. Environ. Pollut. 130, 427-436.

Salt, D.E., Blaylock, M., Nanda-Kumar, P.B.A., Dushenkov, V., Ensley, B.D., Chet, I., Raskin, I., 1995. Phytoremediation: a novel strategy for the removal of toxic metals from the environment using plants. Biotechnol. 13, 468474.

Saric, M.R., Stojanovic, M., Babic, M., 1995. Uranium in plant species grown on natural barren soil. J. Plant Nutri. 18, 1509-1518.

Shahandeh, H., Hossner, L.R., 2002. Enhancement of uranium phytoaccumulation from contaminated soils. Soil Sci. 167, 269-280.

Shahandeh, H., Lee, J.H., Hossner, L.R., Loeppert, R.H., 2001. Bioavailability of uranium and plutonium to plants in soilwater systems and the potential of phytoremediation. In: Gobran, G.R., Wenzel, W.W., Lombi, E. (Eds.), Trace Elements in the Rhizosphere. CRC Press LLC, London, UK, pp. 93-124.

Sharples, J.M., Meharg, A.A., Chambers, S.M., Cairney, J.W.G., 2000. Mechanism of arsenate resistance in the ericoid mycorrhizal fungus Hymenoscyphus ericae. Plant Physiol. 124, 1327-1334.

Sheppard, S.C., Sheppard, M.I., Gallerand, M.-O., Sanipelli, B., 2005. Derivation of ecotoxicity thresholds for uranium. J. Environ. Radioact. 79, 55-83.

Tu, C., Ma, L.Q., 2002. Effects of arsenic concentrations and forms on arsenic uptake by the hyperaccumulator ladder brake. J. Environ. Qual. 31, 641-647. 
Weiersbye, I.M., Straker, C.J., Przybylowicz, W.J., 1999. Micro-PIXE mapping of elemental distribution in arbuscular mycorrhizal roots of the grass, Cynodon dactylon, from gold and uranium mine tailings. Nuc. Instru. Meth. Phys. Res. B 158, 335-343.

Xu, L.C., Wang, Y.X., Liu, J.W., Lu, X.S., Liu, Y.C., Liu, X.Y., 2002. Radioactive contamination of the environment as a result of uranium production: a case study at the abandoned Lincang uranium mine, Yunnan Province, China. Sci. China (B) 45, 11-19.

Zhao, F.J., Dunham, S.J., McGrath, S.P., 2002. Arsenic hyperaccumulation by different fern species. New Phytol. $156,27-31$.

Zhu, Y.-G., Shaw, G., 2000. Soil contamination with radionuclides and potential remediation. Chemosphere 41, 121128. 